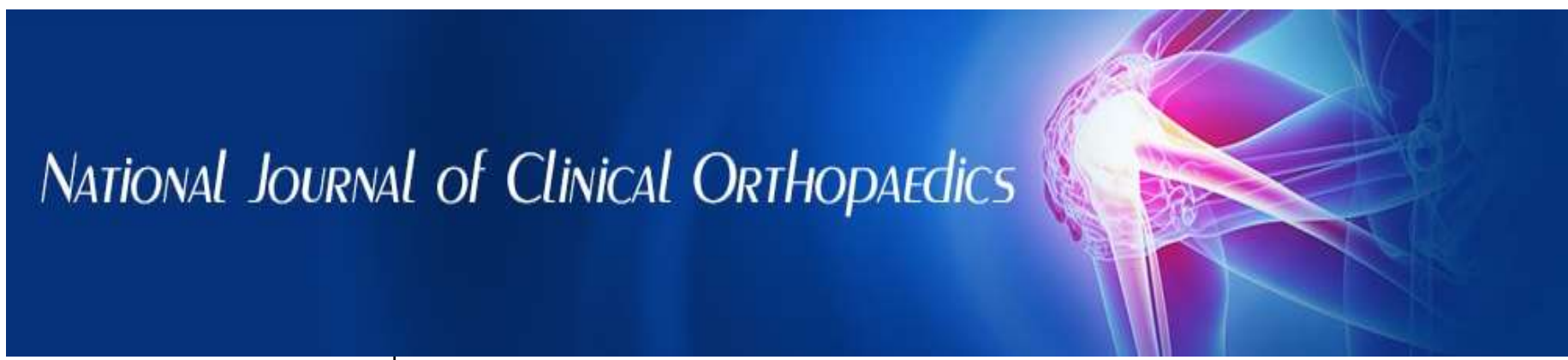

ISSN (P): 2521-3466

ISSN (E): 2521-3474

(C) Clinical Orthopaedics www.orthoresearchjournal.com 2021; 5(3): 164-166

Received: 18-05-2021

Accepted: 20-06-2021

Dr. Sujanatheja JS

Assistant Professor,

Orthopaedics Department,

JSS Medical College Mysuru,

Karnataka, India

Dr. Pavankumar Patted

Junior Resident, Orthopaedics

Department, JSS Medical College

Mysuru, Karnataka, India
Corresponding Author:

Dr. Pavankumar Patted

Junior Resident, Orthopaedics

Department, JSS Medical College

Mysuru, Karnataka, India

\section{Management of lateral end clavicle fractures using lateral clavicle locking plate: A prospective study}

\author{
Dr. Sujanatheja JS and Dr. Pavankumar Patted
}

DOI: $\underline{\text { https://doi.org/10.33545/orthor.2021.v5.i3c.312 }}$

\section{Abstract}

Background: The study was conducted to assess the functional outcome of clavicular lateral clavicle locking plate for displaced lateral end clavicle fractures using Constant Murley score.

Materials and Methods: This study include total of 15 cases with displaced lateral end clavicle fractures satisfying the inclusion criteria treated with lateral clavicle locking plate. Patients were followed up at 1 st month, 2nd month and 6th month, the functional outcome was assessed using Constant Murley score and the radiological outcome was also assessed.

Results: In our study, 15 cases treated with lateral clavicle locking plate $6.7 \%$ of patients had excellent outcome and $66.7 \%$ had good outcome with plate backout and dislocation seen in6.7\% of patients.

Conclusion: locking plate have a good functional outcome for lateral end clavicle fractures. Addressing the coracoclavicular ligaments in case of lateral locking plate is of utmost importance in comminuted lateral end clavicle fractures.

Keywords: Lateral end clavicle fracture, lateral clavicle locking plate, acromioclavicular joint dislocation, clavicle fracture

\section{Introduction}

Fractures of the clavicle are common injuries with an incidence of 29 per 100,000 population per year ${ }^{[1]}$. It accounts for $2.6-4 \%$ of the total adult fractures. Lateral end fracture constitutes $21-28 \%$ of all clavicle fractures. Of these $10-52 \%$ are displaced fractures ${ }^{[2]}$. Minimally displaced fractures of the lateral end of the clavicle can be managed nonoperatively with good clinical outcome, displaced and comminuted fractures of the lateral end of clavicle have a higher rate of non-union ${ }^{[3]}$.

There are numerous surgical techniques for the treatment for these fractures. If surgery of lateral end clavicle fractures is indicated, many implants or surgical methods are available, including Kirschner wires, coracoclavicular screw fixation, hook plate fixation, or locking plate fixation. Although there are many types of operative procedures, no procedures are considered to be the gold standard treatment. The optimal treatment of unstable lateral clavicle fractures is still controversial. The use of a pre-contoured superiorly placed locking plate and screws, for the lateral end of the clavicle, is a recent development. It is advocated as a satisfactory technique for fixation of displaced fractures of the lateral clavicle due to good results seen with this fixation ${ }^{[1]}$.

\section{Materials and methods}

15 cases with lateral end clavicle fractures admitted in JSS Hospital in a period of September 2016 to April 2019 satisfying the inclusion criteria were treated with lateral clavicle locking plate.

\section{Inclusion criteria}

1. Displaced lateral end clavicle fracture.

2. Age $>18$ years.

\section{Exclusion criteria}

1. Pathological fractures.

2. Medial and midshaft clavicle fractures.

3. Ipsilateral-humerus head/neck fracture. 


\section{Results}

There were total of 15 patients, among them 12(80\%) were male and $3(20 \%)$ were female. Right sided lateral end clavicle fracture was seen in $9(60 \%)$ and left in $6(40 \%)$ patients. Road traffic accidents was the cause of trauma in $9(60 \%)$ and fall in $6(40 \%) .10(66.6 \%)$ patients were type 2 Neer's fracture and $5(33.3 \%)$ were type 3 Neer's fractures. $9(60 \%)$ patients were less than 40 years of age, $3(20 \%)$ patients were of $40-50$ years and $3(20 \%)$ patients were more than 50 years.

Constant murley score $6.7 \%$ of patients had excellent outcome and $66.7 \%$ had good outcome. The mean duration of fracture union was 13.3 weeks $3(20 \%)$ patients had Acromioclaviculardislocation and $1(6.7 \%)$ patient had Plate backout with dislocation.

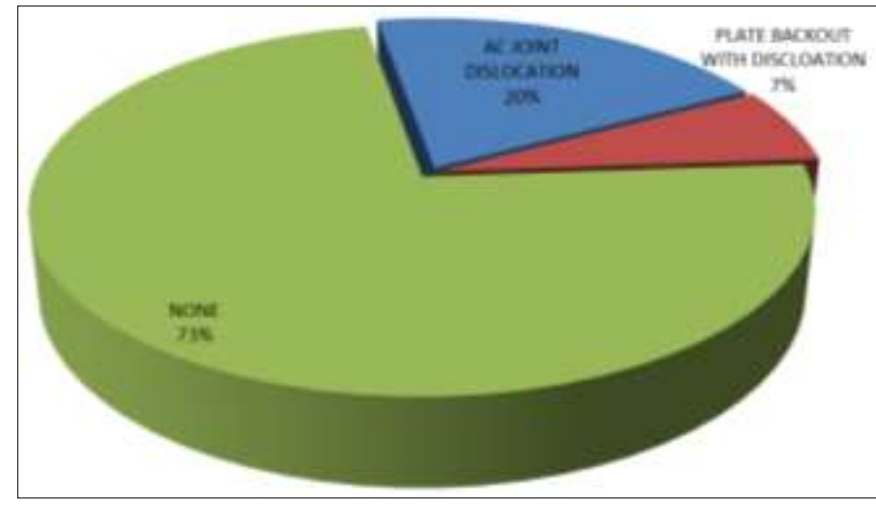

Fig 1: Complications
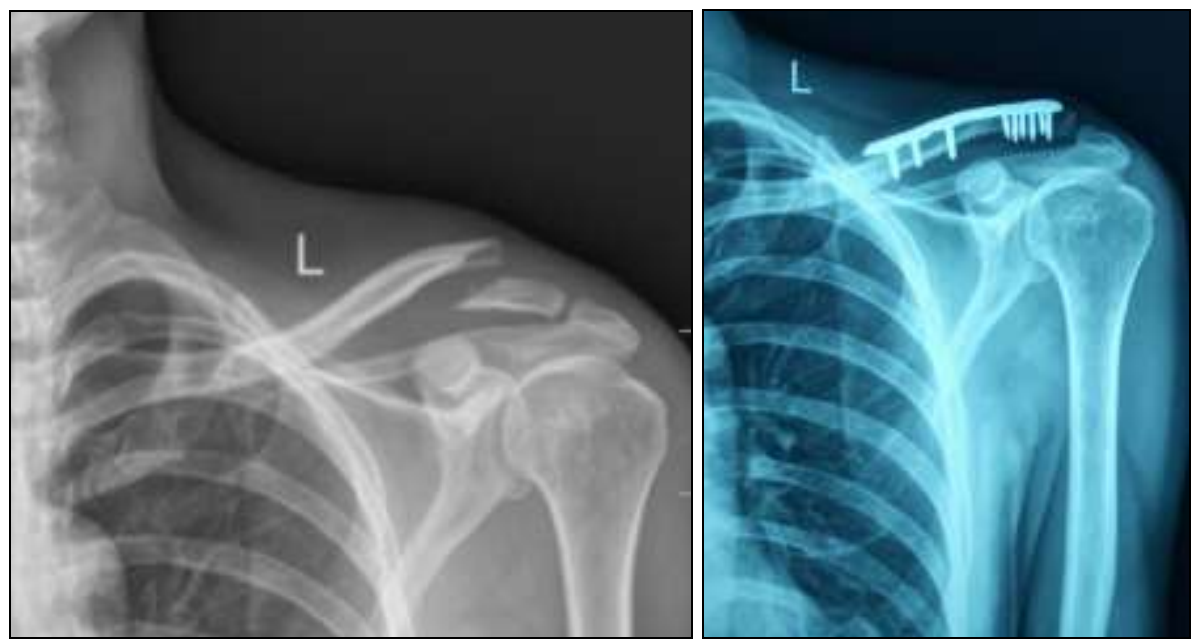

\section{Discussion}

Robinson et al. ${ }^{[4]}$ reported lateral clavicle locking plate leads to sufficient stabilization and good functional outcome with high patient satisfaction when used for displaced lateral clavicle fractures. In fractures between the coracoclavicular ligaments in combination with a rupture of the conoid ligament (Neer II) the reconstruction of the $\mathrm{CC}$ ligaments additionally to locking plate osteosynthesis showed superior biomechanical stability results. In our study also we found the same results.

Shin et al. ${ }^{[5]}$ reported satisfactory clinical outcomes and high union rates using anatomic clavicle LCP fixation in patients with unstable distal clavicle fractures, even when the lateral fragment was small. They tried to insert more than 4 small screws in the distal fragment to achieve secure fixation. The aim of open reduction and internal fixation is to give absolute stability but it is challenging to achieve in cases of unstable distal-third clavicle fractures, particularly in comminuted distal fragments. In some comminuted fracture cases, it is difficult to insert even 2 distal screws. Although recent studies have demonstrated satisfactory clinical and radiologic outcomes after treating Neer type II distal clavicle fracture using anatomic clavicle LCP, we thought that it would be difficult to control the force of the trapezius pulling on the proximal fragment superiorly if we could not insert enough screws in the distal fragment with anatomic clavicle LCP.

Fleming et al, reviewed 19 patients who underwent surgery with superior pre-countered locking plates for displaced distal-third clavicle fractures ${ }^{[6,7,8]}$. All patients achieved union by 4 months and no plates have been removed. In our study also, the mean union time was same around 13.3 weeks or 4 months. The rate of union in the present study were similar to other studies by Lee et al. ${ }^{[9]}$ and Rokito et al. ${ }^{[10]}$
Limited literature is there on outcomes with superior locking plates for unstable distal clavicular fractures. Fixation failure in the distal fragment with the use of locking plates for clavicular fractures has been reported ${ }^{[11]}$

Locking plates are fixed angle constructs which have greater resistance to screw pullout ${ }^{[12]}$. However, this concept does not take into account the significant displacing forces acting at the lateral end of the clavicle. The forces causing clavicle displacement are the weight of the arm, the pull of pectoralis major, pectoralis minor and latissimus dorsi muscles, scapula rotation, and the pull of the sternocleidomastoid muscle. A locking plate placed superiorly over the lateral end of the clavicle does not adequately neutralize all the forces acting at the fracture site, which act predominantly to pull the lateral fragment inferiorly. Hence in comminuted fractures, it is very difficult to have good outcome.

\section{Conclusion}

Different techniques have been used to achieve fixation of lateral end clavicle fractures. Care should be taken when using a lateral clavicle locking plate particularly when the lateral fragment is small and comminuted. Implant related complications are very less and hence early implant removal is not required. AC joint dislocation in locking plate was one of the complications. The reconstruction of the Coracoclavicular ligaments additionally to locking plate osteosynthesis can show superior biomechanical stability results. In cases with far cortex comminution or avulsion injuries of $\mathrm{CC}$ ligaments, where it would be difficult to get screw purchase through the avulsed or comminuted fragment, chances of implant pullout is more. Such cases should be treated with lateral clavicle locking plate with 
reconstruction of $\mathrm{CC}$ ligaments. However large sample, with longer followup with comparative studies with other modalities is needed.

\section{References}

1. Sajid S, Fawdington R, Maneesh Sinha M. Locking plates for displaced fractures of the lateral end of clavicle: Potential pitfalls. Int J Shoulder Surg 2012;6(4):126-9.

2. Balaji Sambandam, Rajat Gupta, Santosh Kumar, Lalit Maini. Fracture of distal end clavicle: A review journal of clinical orthopaedics and trauma 2014;5:65-e73.

3. Edward Perez A. Fractures of shoulder, arm and forearm, Campbells Operative Orthopaedics 12th ed, 2836 pg.

4. Robinson CM, Akhtar MA, Jenkins PJ, Sharpe T, Ray A, Olabi B. Open reduction and endobutton fixation of displaced fractures of the lateral end of the clavicle in younger patients. J Bone Joint Surg Br 2010;92-B(6):811816.

5. Shin SJ, Ko YW, Lee J, Park MG. Use of plate fixation without coracoclavicularligament augmentation for unstable distal clavicle fractures. J Shoulder Elbow Surg 2016;25:942-8.

6. Fleming MA, Dachs R, Maqungo S, du Plessis JP, Vrettos BC, Roche SJ. Angularstable fixation of displaced distalthird clavicle fractures with superiorprecontoured locking plates J Shoulder Elbow Surg 2015;24(5):700-4.

7. Oh JH, Kim SH, Lee JH, et al. Treatment of distal clavicle fracture: A systematic review of treatment modalities in 425 fractures. Arch Orthop Trauma Surg 2011;131(4):525-33.

8. Hessman M, Gotzen L, Kirchner R, et al. Therapy and outcome of lateral clavicular fractures. Unfallchirug 1997;100(1):17-23.

9. Lee KW, Lee SK, Kim KJ, Kim YI, Kwon WC, Choy WS. Arthroscopic-assisted locking compression plate clavicular hook fixation for unstable fractures of the lateral end of the clavicle: a prospective study. IntOrthop 2010;34(6):839-45.

10. Rokito AS, Zuckerman JD, Shaari JM, Eisenberg DP, Cuomo F, Gallagher MA. A comparison of nonoperative and operative treatment of type II distal claviclefractures. Bull Hosp Jt Dis 2002;61(1-2):32-3.

11. Perren S, Claes L. Biology and biomechanics in fracture management. In: Ruedi $\mathrm{T}$, Murphy $\mathrm{W}$, editors. AO principles of fracture management. New York: Theime 2000, 7-31.

12. Largo RD, Rudin MA, Hotz TK, Valderrabano V, Käch KK. Anatomic reconstruction of unstable lateral clavicular fractures. J Trauma 2011;71:1348-51. 